\title{
Initiatives for Teaching Energy Modelling to Graduate Students
}

\author{
Denis Lavigne \\ Royal Military College St-Jean, St-Jean-sur-Richelieu, Quebec, Canada
}

Copyright $(2016$ by authors, all rights reserved. Authors agree that this article remains permanently

open access under the terms of the Creative Commons Attribution License 4.0 International License

\begin{abstract}
The Institut de l'énergie Trottier of the École Polytechnique de Montréal offers four new masters in energy programmes. Enrolling graduate students come from diverse backgrounds and there is a need for an intense introductory course on energy modelling. Such a new course has been created to propose a hands-on experience that enlightens their understanding of what energy modelling is. Powerful yet simple tools such as OSeMOSYS and LEAP are used. Links with economics and environmental issues are discussed. This paper presents an overview of the various topics studied in class and will allow anyone interested in creating a similar course to have a starting point to help them on their quest to develop highly qualified professionals. Individuals completing this course gain a general overview of the field and are ready to pursue further study with the necessary knowledge to do so. It will help them to communicate their work with professionals that may not be used to work with operation research (OR) specialists. The approach is also useful for anyone wanting to learn more on the subject. A course outline completes the paper.
\end{abstract}

Keywords Energy Modelling, Optimization, Simulation, OSeMOSYS, LEAP, Environmental Policies

\section{Introduction}

Which topics shall be included in a course outline on energy modelling? Which software could be used to tackle problems associated with the energy sector? How can government officials develop policies to meet medium-to-longterm targets on $\mathrm{CO}_{2} \mathrm{e}$ emissions (and what is $\mathrm{CO}_{2} \mathrm{e}$ )? How can one learn and teach about the subject and communicate his/her findings to the non-experts decision makers?

The Institut de l'énergie Trottier [1] of the École Polytechnique de Montréal [2] offers four new masters in energy programmes [3]. Enrolling graduate students come from diverse backgrounds. In order to answer questions as the ones above, a new course on energy modelling has been created [4] which proposes an hands-on experience that enlighten their understanding of what energy modelling is.

Students are graduates from engineering, economics, mathematics, environmental or other fields. Some of them know a lot about technical issues related to technologies (energy efficiency, life duration, needed input and effective output, ...), while others are familiar with the law of supply and demand or elasticity issues, the impact of discounting the costs in a long-term analysis, algebraic mathematical modelling languages, or policy-making under severe greenhouse gases limitations. But none of them have a basic knowledge of all these topics and of some specific software used to tackle such issues using an integrated approach. The proposed course outline is particular in the fact that it proposes an overview which encompasses these important notions. It (of course) can not be an in-depth development on the subject but it does offer a coherent multi-disciplinary approach which reflects some of the work done in energy modelling worldwide. Individuals able to grasp a good knowledge of the topics included in this course will be well-prepared to pursue their studies on the subject.

A fine example of a follow-up graduate course is proposed by Montreal's HEC business school: 6-639-13: Modèles d'aide à la décision en énergie (see [5]). It offers a wide range of applications on energy modelling using more advanced mathematical models such as mixed-integer, nonlinear and stochastic programming. It also presents multiobjectives optimization. Students that choose this path confirm that both courses are a great duo in learning energy modelling.

A course on Energy Systems Modelling is offered at the University College Cork (UCC) of Cork, Ireland (see [6]). It proposes TIMES instead of OSeMOSYS. UCC's course seems to be more heavily technically detailed and less accessible for students coming from wider backgrounds. It would be another great complement course to the one proposed at Montreal's Polytechnique.

This paper proposes an overview of a new course on energy modelling and presents its course outline. Despite its use of appropriate expertise on particular science issues, it can also be read as an introduction to the subject by skipping parts of the paper without losing the insight given by such an approach.

\section{Objectives}

The main objective of the paper is to describe the content of an intense introductory new course on energy modelling 
for students coming from various backgrounds in order to prepare them for further study in the field. The proposed hands-on experience approach offers to students, experts and decision makers of the energy sector a common ground on which they can build to analyse, discuss and share knowledge on different issues related to the field.

Students will discover issues about energy modelling and ways to work in such an environment. Experts will gain by being in contact with what is considered to be an innovative approach to teach and learn about it using the given course outline as a starting point for creating a course of their own. Decision makers will understand how scientists can assist them in the development of coherent and sound policies to answer difficult problems. Above all, the underlined goal is to help all the actors of the energy sector to have some common grounds to communicate about the important issues ahead for society.

\section{Course Description}

The proposed course on energy modelling is given over a 13-week period of 3 hours each in class (work outside class is also expected). It is based on an integrated techno-economic bottom-up approach (these terms will be explained in the text). It implies a disaggregated description of all technologies involved in all the different sectors linked to energy: production, consumption (residential, commercial/institutional, industrial and agriculture), importations and exportations of all types of energy fuels. Optimization and simulation software are used.

But who uses such tools? What are the real world problems faced by our leaders?

\subsection{Cities, States and Countries Need Energy Mod- elling}

In the province of Quebec (Canada), many cities have produced local inventories of their energy use and greenhouse gases (GHG) emissions. This is the basic level of energy modelling. The course being taught in french, students must navigate through documents produced for cities within the province of Quebec, Canada, such as the small city of StJean-sur-Richelieu [7] or the province capital, which is Quebec [8] (many similar documents are available in english; see for example the region of Chicago [9]). States examples of studies involving energy are also analysed (see California [10]). Tools are proposed by the US Environmental Protection Agency (USEPA) to assist experts to accomplish such a task [11]. The case of Canada is presented in [12]. This document offers a comprehensive study that is an excellent introduction to the subject (see Figure 1 for an example of long-term results). A country such as Ireland proposes interesting documents to understand the problems faced by its government on long-term energy planning (see for example [13]). Canada's National Inventory Report [14] is another interesting document to know more about the country's energy use.

Discussions on medium-to-long-term scenarios are encouraged in class (for example on negotiation on emissions targets among very diverse countries). It is important to know the difference between $\mathrm{CO}_{2}$ and $\mathrm{CO}_{2} \mathrm{e}$ (or $\mathrm{CO}_{2}$-eq): carbon dioxyde $\left(\mathrm{CO}_{2}\right)$ is one type of greenhouse gas and $\mathrm{CO}_{2} \mathrm{e}$ is an equivalent of $\mathrm{CO}_{2}$ for $\mathrm{GHG}$ emissions purposes. For example, emission of one ton of $\mathrm{CH}_{4}$ is equivalent to 25 tons of $\mathrm{CO}_{2}$ (see [15]). This course is not about setting limits on greenhouse gases emissions by 2020, 2050 or 2100 . We emphasize on the fact that the objective is to assist decision makers in finding out how technological decisions and government policies can be used to reach a specific target that they select.

\subsection{The Approach}

The course proposes an integrated techno-economic bottom-up approach. It is (1) integrated in the sense that it includes all the energy "food-chain" from the extraction of primary energy fuels to its modification into final energy that is used by technologies to satisfy some demand. For example, crude oil can be transformed into gasoline for cars to satisfy the need to go from point A to point B. This need to go from a place to another by car can also be met by using electric cars using cleaner energy such as hydro-electricity. Competition is not only between electric cars and gasoline cars but must involve the costs associated through all the steps of the process. It is (2) techno-economic because technical data (efficiency, life expectancy, annual availability, etc.) and economic data (investment prices, maintenance cost, fuel cost, etc.) are used. It also is (3) bottom-up because it uses a very detailed description of a region's long list of production, transformation and demand technologies which are all competing to satisfy the disaggregated needs of that specific region. For example, the residential sector is broken down into many individual demands such as water heat, space heat, appliances, etc., and each one of these demands must be satisfied using possibly many competing technologies. Decisions made in the residential sector influence the ones that need to be made in the transport sector and all other sectors as well.

Some time must also be allowed for issues on economics such as supply and demand, maximization of social surplus and the concept of marginal analysis. Consumer behaviour [16] is also discussed as it can have a low-costhigh-importance to solve energy-related environmental issues. The behaviour can be a "morally" new attitude towards energy choices or simply an economic reaction to price (which is known as elasticity). A good introduction to such economic issues is presented in [17]. Finally, the effect of discounting on long-term decisions must be discussed. A change in the discount rate can greatly affect decisions for long-term scenarios.

\subsection{Simulation}

The "simple" task of modelling the current existing energy sector of a country involves an important amount of work. The Long range Energy Alternatives Planning system (LEAP) software $[18,19]$ can assist a professional in performing such task. Moreover, it allows one to simulate different short-medium-to-long-term scenarios. LEAP's learning curve is quite smooth, thanks to its powerful training material readily available and accessible to students [20]. It is based on a fictive region of the world called Freedonia. (Figure 2) gives an example of a LEAP's screenshot.

This training material fully describes the steps that need to be implemented in order to model the current and future situation of a country (or a city, a state or a group of countries). Students will appreciate to create a detailed description of an 


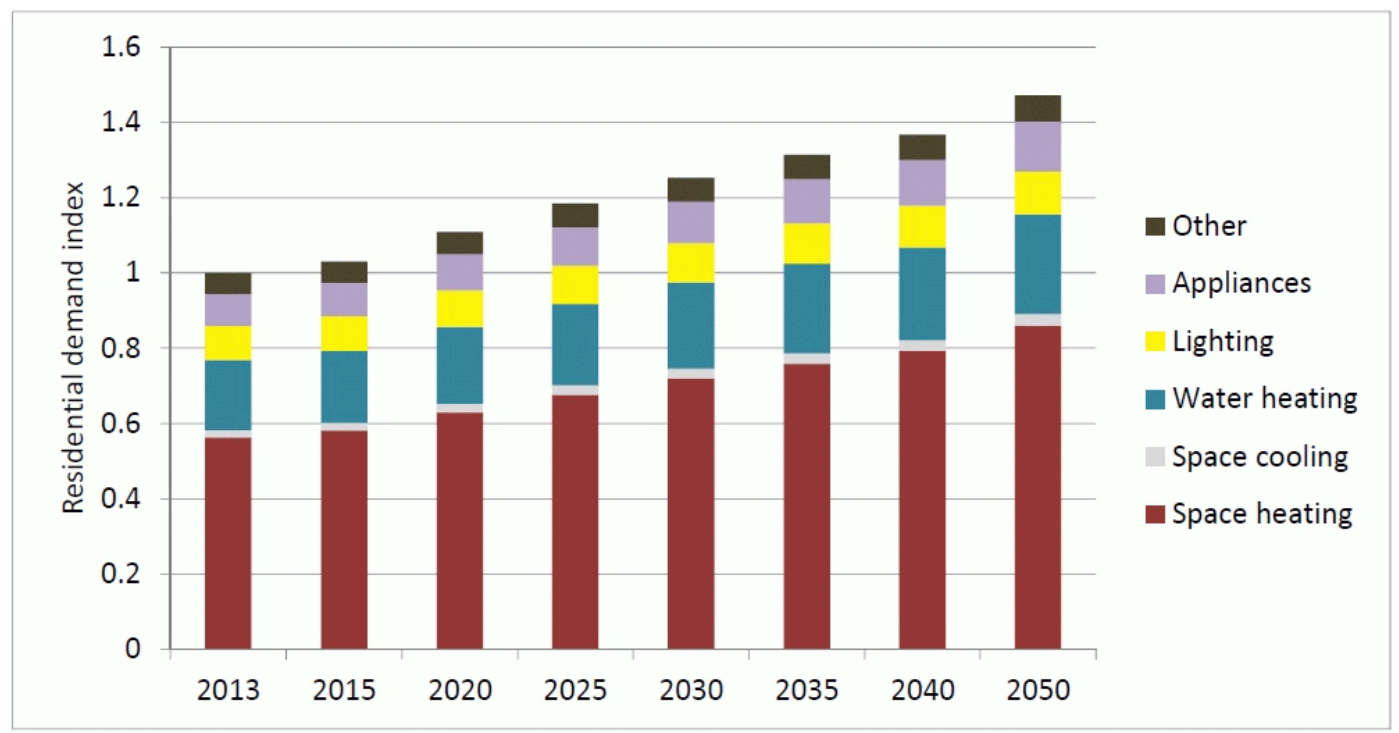

Figure 1. Residential Useful End Use Energy Demand by Service

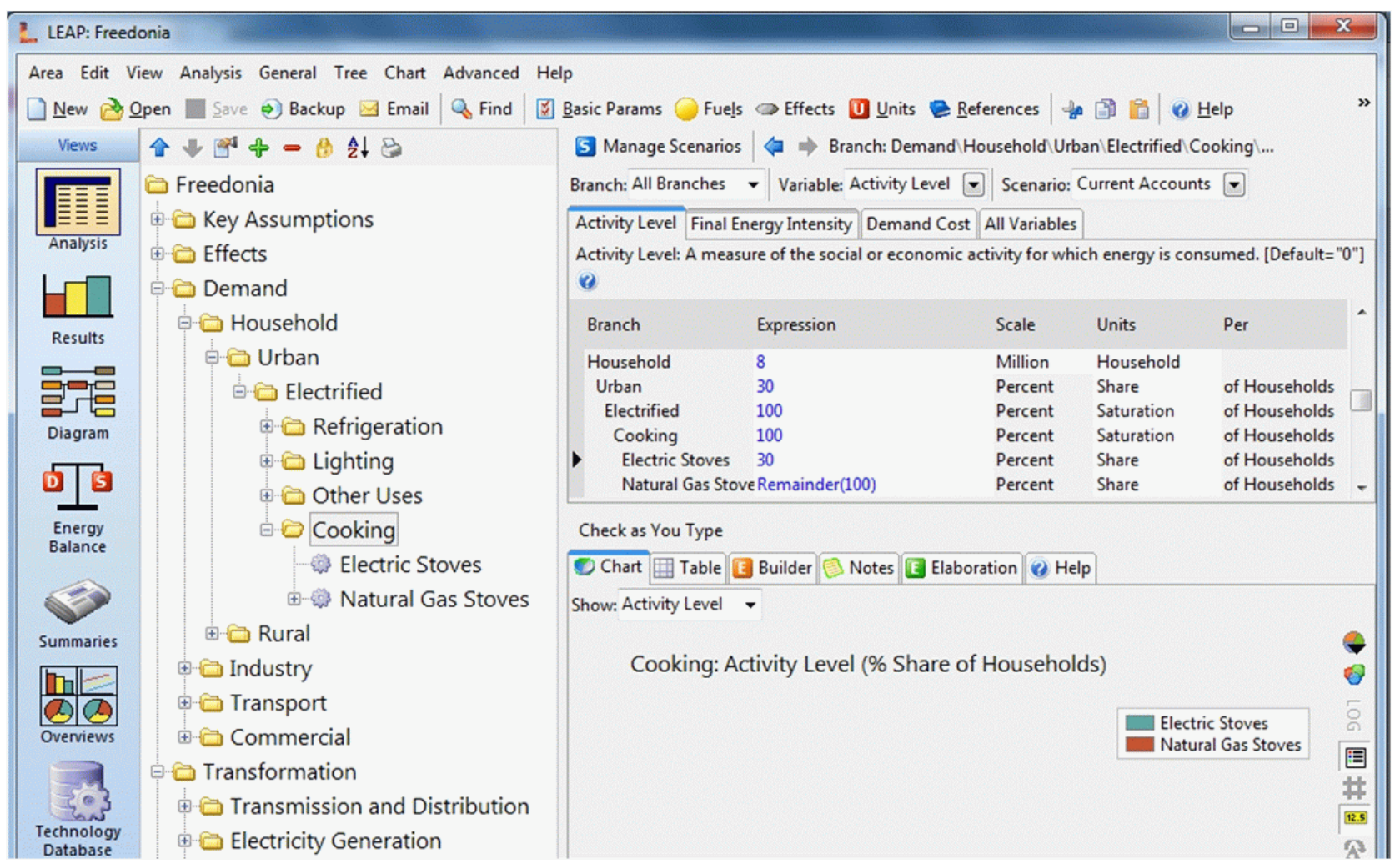

Figure 2. LEAP's Screenshot

entire energy system through its technological components. Teaching is made easy by first representing the residential demand sector and the energy generation, transmission and distribution needed to satisfy the residential demands. A longterm scenario is proposed and results are discussed. This scenario is the basecase, reference or business-as-usual scenario. An alternative demand-side management (DSM) scenario is proposed. This is an easy yet powerful way to analyse the impact of new and more energy efficient technologies.

Other chapters of the training material include the description of the industrial, transportation and commercial sectors, a detailed description of the supply side of the energy sector and many interesting subjects such as a cost-benefit analysis and a transportation study.

Moving through the chapters, students (and decision makers) get to learn about numerous energy-related and technology-related topics such as the following: working with energy units (which is an underestimated topic), describing a technology through its technical and economic characteristics, how to analyse results effectively, what is a reference scenario and an alternative scenario, transmission losses, what is a load curve and a load factor and the impact of demand-side management over these, finding what an energy balance is, the effect of different policies on technological choices, and many other technical issues involved in energy modelling. (Figure 3) gives an example of the impact of a flat load curve (due to some demand-side management versus a reference scenario) on the necessary installed production capacity to satisfy energy consumption. Note that in this example the total amount of energy produced is identical 
in both scenarios. The load factor varies from $48.8 \%$ in the Reference Scenario to $63.4 \%$ in the alternative Demand-Side Management Scenario.

LEAP is a very powerful tool for simulations. It is available free of charge for students. They must register through the new LEAP homepage [21] (June 2016). Being part of the LEAP community is a great addition to one's network with energy professionals.

The last section of LEAP's training material presents a link between LEAP's simulation capability and optimisation via OSeMOSYS, which is the next topic to be studied in class.

\subsection{Optimization}

Optimization can be seen as an extension to simulation. It offers the same coherence in decisions to satisfy multiple end-use demands. The important difference is that optimization will not "simply" show the results and impacts of a particular scenario but it rather proposes optimal decisions in the sense that the technological and energy choices will maximize or minimize a particular objective. For example, the usual objective in techno-economic energy models is the minimization of the total discounted cost of the whole energy system (including the cost of fuels, investment, maintenance and level of activity of all technologies involved in the system for energy production and consumption).

\subsubsection{Linear Programming}

The approach adopted here is similar to the well-known TIMES model (The Integrated MARKAL-EFOM System [22]) used in many countries. The TIMES model is supervised by the ETSAP organisation (Energy Technology Systems Analysis Program [23]). TIMES is a linear programming model. Although most students know about linear programming, a brief overview of linear programming is compulsory and must include marginal analysis. The marginal value associated to the constraints on GHG emissions is an important result that helps to recognize the magnitude of the financial impact associated with a particular limit on emissions. Interesting basic general models can be found in [24] and solved using Excel's Solver.

\subsubsection{Mathematical algebraic modelling languages}

Although widely used in school as a learning tool and albeit its very ease of use, Excel's Solver is usually not the proper tool for large models involving many decisions over a long-term horizon. Specialized mathematical algebraic modelling languages are available. These languages are not typical programming languages such as $\mathrm{C \#}$ or other quite complex tools that would require a steep learning curve and could not be part of the proposed course. Algebraic modelling languages are on the contrary fairly simple to "read" for beginners and eventually not to difficult to create for someone with a proper basis in mathematics (which shall be the case with graduate students from an engineering school). Some may argue that learning how to use an algebraic modelling language asks too much of a learning curve. The answer to this issue is that (1) this course is proposed to highly motivated graduate students and (2) one can follow the rest of the course without having too much difficulties even if he/she does not fully grasps this part of the material.
TIMES is created using GAMS (General Algebraic Modeling System [25]). A very simple example of a transportation problem [26] and a model library [27] are available. Even though GAMS would be a nice tool for this course (other similar products would also be of great value: see among others AMPL [28] and OPL [29]), the freely available GLPK (GNU Linear Programming Toolkit [30]) is used in class. This package includes the mathematical programming language GNU Mathprog and a solver glpsol for linear programming problems. The original OSeMOSYS model has been created using GLPK [31] (a GAMS version is also available).

The best way to learn mathematical algebraic modelling languages is to create a basic example such as the transportation problem mentioned above. The mathematical model, its GLPK equivalent representation and its associated data file are given in the annex to this paper.

\subsubsection{OSeMOSYS Energy Model and the UTOPIA example}

OSeMOSYS has been officially presented for the first time at the 2010 International Energy Workshop in Stockholm. It offers a basic energy model that leads students and nonexperts in learning much of the material that shall be known by future users of more powerful models like TIMES. It is argued that OSeMOSYS avoids the complexity of models such as TIMES and allows to focus on learning the concepts of energy modelling. Students wanting to pursue they work in energy modelling may have to eventually face more complex models and will be ready to do so after this course.

Moreover, a much appreciated link is available between LEAP and OSeMOSYS, allowing one to use LEAP not only as a simulation tool (as it basically is) but to extend it for optimization without causing much trouble to the user. The link is invisible to the user and analyses such as the one proposed in the last section of LEAP's training material (exercice of optimization using the LEAP-OSeMOSYS link as mentionned previously in the text) is seen as an excellent tool for the students to appreciate the addition of optimization to an original simulation-based approach.

OSeMOSYS, as TIMES, is made of a list of decisions that must be taken in order to minimize the total discounted cost over some time-horizon to satisfy all the demands of a particular region. Decisions must respect a long list of constraints imposed on the system. The complete model is fully described in [32]. The GLPK version of the model is available at [33].

Widely used models are trusted to be fine tuned, mathematically coherent and correctly coded. Understanding TIMES' code is an enormous challenge. On the contrary, although not as simple as it claims to be, reading OSeMOSYS' code is possible for an experienced modeller. Minimally, its basic structure can be presented to students and newcomers to the field.

The OSeMOSYS model is available for use by anyone wanting to represent his/her own region. It includes no specific data of any particular region. A user must create a data file that will represent the region under study. An example of a small scale data file called UTOPIA, coherent with the OSeMOSYS model, is also available (see [33]). Although very simple, it offers enough possibilities for a user to feel like he/she is working on a similar-to real-life analysis. Solving 


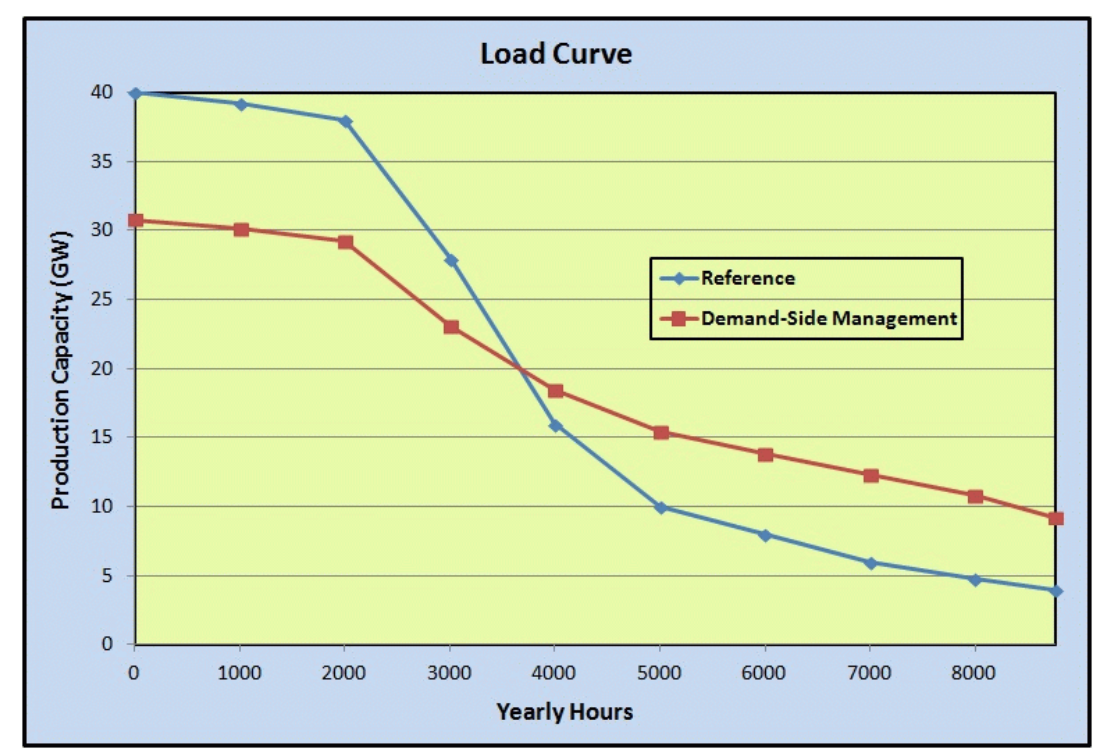

Figure 3. The impact of demand-side management

the OSeMOSYS-UTOPIA problem is a matter of seconds. Results are stored in an Excel solution file which is created automatically.

\section{Course Outline}

This is a 13-week course of 3 hours per week. Here is a detailed week-by-week description of the material covered in class.

\subsection{Weeks 1 and 2: A Country's Overview}

Weeks 1 and 2 include the presentation of the course outline and the installation of the OSeMOSYS and LEAP software. Prior contact shall be made with LEAP's management team. Students will have to register to LEAP (free of charge for a year for students). The case of a country is discussed. Ireland has been selected and many of the country's specific issues are presented:

1. A look back on the country's history on energy, demands, technologies, data, population and economy;

2. Kyoto's protocol, European Union's (EU) greenhouse gases (GHG) emissions targets and Ireland's targets;

3. Targets' fairness among countries, marginal value of reducing GHG emissions, importance of the year of comparison (base-year or reference year), influence of the BRIC countries: Brazil, Russia, India and China;

4. Emissions under the Energy Trading Scheme (ETS) and those which are not (Non-ETS), particular"in-house" targets such as renewable energy for transport;

5. Post-Kyoto's targets for EU and Ireland;

6. A look at some official Irish documents on energy.

Most students will be surprised by all the related topics presented. For most if not all of them, it is the first time they are in contact with such detailed description of full-scale real-life complex issues on energy from such a point of view. The important aspect of these two weeks is to immerse the students in the vast scheme of a country's energy system from a technical, economical, environmental and political perspective.

\subsection{Week 3: Economic Issues}

Many students with engineering background have poor knowledge of economics. Week 3 fills in the gap with energy related topics on economics.

1. Past-present-future and the discounting value of money, and what it means for a decision-maker;

2. Partial vs general equilibrium;

3. Supply and demand, consumer, producer and social surpluses;

4. Elasticity (its relationship with consumer's behaviour and the deterministic approach for individual end-use demands).

\subsection{Weeks 4 to 6: Simulation using LEAP}

Weeks 4 to 6 offers to the attendees the opportunity to build a complete energy model of a fictive region of the world.

1. Bottom-Up vs Top-Down approach;

2. Integrated techno-economic energy modelling;

3. Long-term demand-driven model;

4. LEAP's training material: Chapter 1 to 3 ; the following topics will be covered:

(a) Basic parameters;

(b) End-use demands;

(c) Energy production and transformation;

(d) Scenario analysis (for example: demand-side management);

(e) Results analysis and reporting issues.

Upon the completion of this section, students will be wellaware of the scale of work involved in building an energy model of a country. They will understand the links between all the different aspects of a region's energy system. 


\subsection{Weeks 7 and 8: Overview on Optimization}

Most students have had a basic course on optimization and linear programming. Nevertheless, mathematical modelling is a challenge and a review of its basic concepts is a necessity. Moreover, very few students have been introduced to general algebraic programming languages such as GAMS or AMPL. Week 8 proposes an introduction to GLPK.

1. Optimization and linear programming;

2. Objective and constraints;

3. Integer and mixed-integer programming;

4. Mathematical modelling;

5. Marginal analysis;

6. Pareto optimality;

7. Introduction to GLPK.

\subsection{Weeks 9 to 11: OSeMOSYS}

The OSeMOSYS optimization model, although considered "simple" by experienced energy modellers, is not such an easy material for the students. The presentation found in [32] fully describes the approach and is followed with the addition of hands-on experience where new demands and their related demand technologies are created. Results are presented using a Pareto analysis, allowing the students to fully grasp the relationship among all the topics presented throughout the course.

1. Overview of the OSeMOSYS model;

2. Overview of the UTOPIA data set;

3. Building an extended UTOPIA data set;

4. Pareto analysis using the resulting model.

\subsection{Weeks 12 and 13: Canada}

A world-renowned expert comes in class to present the case of Canada. The TIMES-Canada model is described and offers to the students the possibility to find out more about their own country's energy system. Again, if some people know about part of it, all of them are amazed by the size, complexity and amount of work involved in facing such issues. Cities, provinces and/or states reports are also presented.

An overview of many websites to know more about technologies and data related to the Canadian energy system are presented (such as the Comprehensive Energy Use Database of Natural Resources Canada [34]). This concludes the course.

\section{Conclusion}

This paper describes a full course on energy-modelling using a techno-economic bottom-up approach. It offers a general overview of an integrated approach on energy modelling and serves as a solid basis to pursue further study in the field. It is an intense hands-on introductory course dedicated to graduate students and decision makers in order to develop highly qualified professionals that can use simple yet powerful tools (simulation and optimization) to gain insight on how one can define coherent long-term energy policies in order for a region (a city, a state, a country or a group of countries) to meet important GHG reduction targets. It has been taught with great success and much appreciated reviews from the attendees.

\section{Acknowledgements}

I am grateful to Dr. Miguel Anjos, professor at the École Polytechnique de Montréal, who gave me the opportunity to create, develop and teach such an innovative course on energy modelling.

\section{Annex}

\section{Optimization Problem}

A company has two production plants and three storage units. Une entreprise possde deux usines de production et trois entrepts. Here are the data representing the production capacities, demands and unit transportation costs. The objective is to meet all the demands at minimal cost.

Table 1. Production Capacities

\begin{tabular}{|c|c|}
\hline Plants & Capacities \\
\hline Seattle & 350 \\
San Diego & 600 \\
\hline
\end{tabular}

Table 2. Demands from Storage Units

\begin{tabular}{|c|c|}
\hline Storage Units & Demands \\
\hline New York & 325 \\
Chicago & 300 \\
Topeka & 275 \\
\hline
\end{tabular}

Table 3. Unit Transportation Costs

\begin{tabular}{|c|c|c|c|}
\hline & New York & Chicago & Topeka \\
\hline Seattle & 25 & 17 & 20 \\
San Diego & 28 & 19 & 16 \\
\hline
\end{tabular}

\section{Mathematical Model}

The sets:

$$
\begin{aligned}
& I:=\text { Plants } \\
& J:=\text { Storage Units }
\end{aligned}
$$

The data:

$c_{i j}:=$ Unit transporation cost from plant $i$

to storage unit $j(\forall i \in I$ and $j \in J$ )

cap $_{i}:=$ Plant production capacity $i(\forall i \in I)$

$\mathrm{dem}_{j}:=$ Storage units demands $j(\forall j \in J)$

The variables:

$x_{i j}:=$ Quantity transported from plant $i$

to storage unit $j(\forall i \in I$ and $j \in J$ ) 
The objective:

Minimization of the total transportation cost:

$$
\sum_{i \in I} \sum_{j \in J} c_{i j} x_{i j}=\sum_{i \in I, j \in J} c_{i j} x_{i j}
$$

The constraints:

$$
\begin{aligned}
& \text { Plants capacities: } \sum_{j \in J} x_{i j} \leq \operatorname{cap}_{i}(\forall i \in I) \\
& \text { Storages Demands: } \sum_{i \in I} x_{i j} \geq \operatorname{dem}_{j}(\forall j \in J) \\
& \text { Non-negativity: } x_{i j} \geq 0(\forall i \in I \text { et } j \in J)
\end{aligned}
$$

\section{GLPK's Model File}

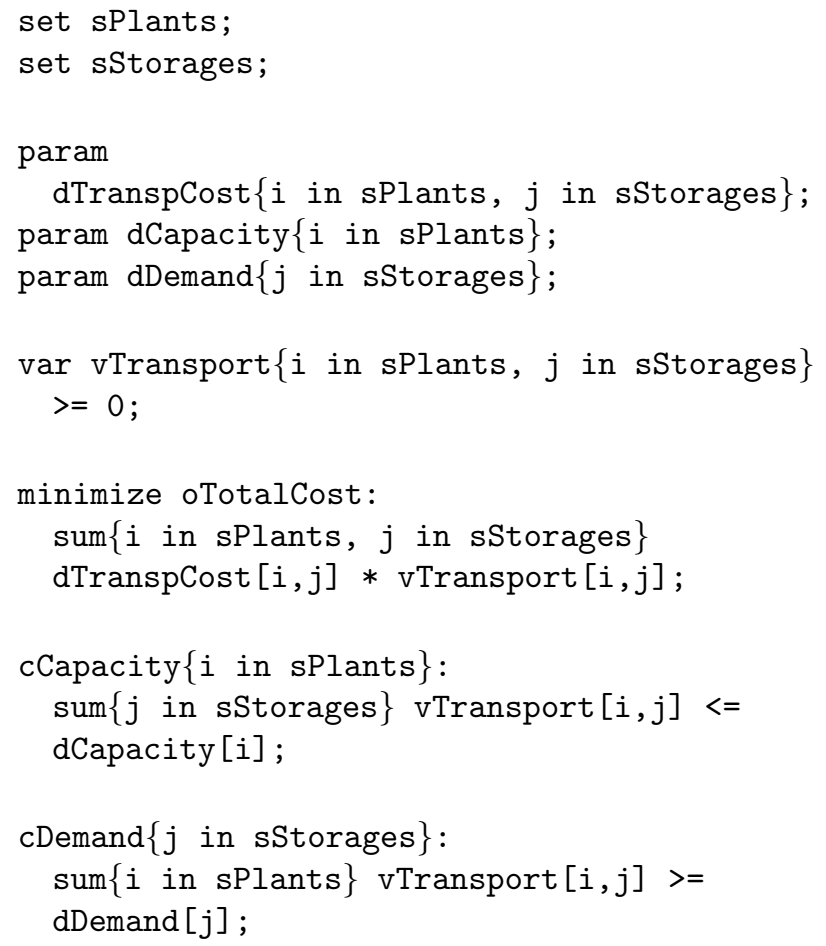

end ;

\section{GLPK's Data File}

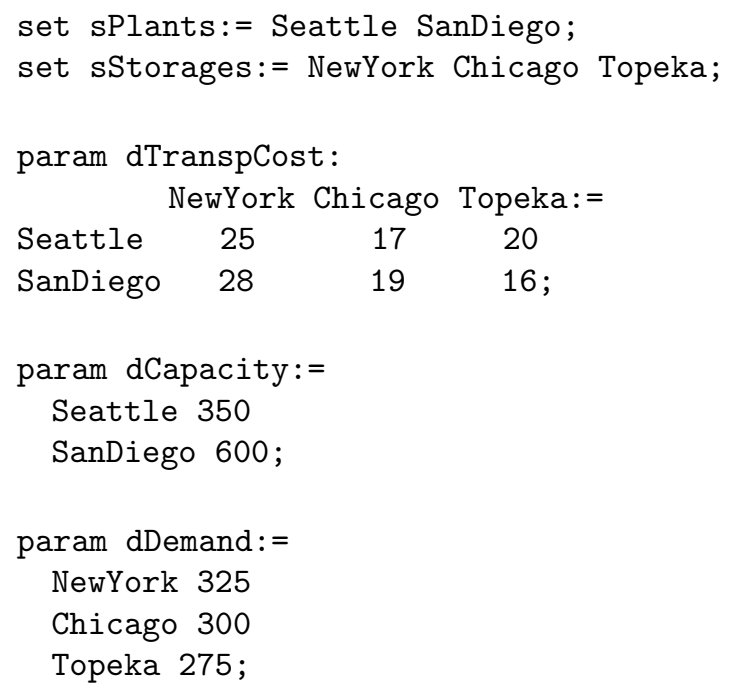

end;

\section{REFERENCES}

[1] Institut de l'énergie Trottier, Online available from http://www.polymtl.ca/iet/en/

[2] Polytechnique Montreal, Online available from http://www.polymtl.ca/en/

[3] New Energy Programmes, Online available from http://www.polymtl.ca/iet/programmes/index.php

[4] Course on Energy Modelling, Online available from http://www.polymtl.ca/etudes/cours/ details.php?sigle $=$ ENE8230

[5] Modèles d'aide à la décision en énergie, Online available from https://zonecours2.hec.ca/sdata/c/attachment/ 6-639-13.E2015.S01/OpenSyllabus/ 6-639-13.E2015.S01_public.pdf

[6] Energy Systems Modelling (UCC), Online available from http://www.ucc.ie/en/media/studyatucc/ international/documentation/ visitingusandnon-eustudents/bookofmodulesfullyear/ visit-book-modules-energy-engineering-2012-2013.pdf

[7] DESSAU, Ville de Saint-Jean-sur-Richelieu, Plan d'action visant la réduction des émissions de gaz à effet de serre, Rapport final, May 2011.

[8] TECSULT, Ville de Québec, Inventaire global des émissions de gaz à effet de serre de l'agglomération de Québec, Rapport final, February 2008.

[9] ICF International, Chicago 2010 Regional Greenhouse Gas Emissions Inventory, May 2012.

[10] California Greenhouse Gas Emission Inventory Program, Online available from http://www.arb.ca.gov/cc/inventory/inventory.htm

[11] Developing a State Greenhouse Gas Inventory, Online available from https://www.epa.gov/statelocalclimate/ developing-state-greenhouse-gas-inventory

[12] Trottier Energy Futures Project, Canada's Challenge \& Opportunity, Transformations for major reductions in GHG emissions, Full Technical Report and Modelling Results, April 2016.

[13] Department of Communications, Energy \& Natural Resources, Ireland's Transition to a Low Carbon Energy Future 2015-2030.

[14] Environment and Climate Change Canada, National Inventory Report 1990-2014: Greenhouse Gas Sources and Sinks in Canada, Executive Summary, 2016.

[15] Intergovernmental Panel on Climate Change (IPCC), Fourth Assessment Report (AR4), Working Group 1 (WG1), Chapter 2, Changes in Atmospheric Constituents and in Radiative Forcing, Table 2.14, page 212.

[16] National Economic \& Social Council, Social and Behavioural Aspects of Climate Change, Background Paper No. 3, Final Report, December 2012.

[17] M. Parkin, R. Bade, Microeconomics: Canada in the Global Environment Plus MyEconLab with Pearson eText, Pearson Education Canada, 2016.

[18] An Introduction to LEAP, Online available from http://www.energycommunity.org/ default.asp?action $=47$ 
[19] Heaps, C.G., 2012. Long-range Energy Alternatives Planning (LEAP) system. [Software version 2015.0.19] Stockholm Environment Institute.

Somerville, MA, USA. www.energycommunity.org

[20] Stockholm Environment Institute, LEAP, Long-range Energy Alternatives Planning System, Training Exercices, February 2016, Updated for LEAP 2015.

[21] COMMEND Community, Online available from http://www.energycommunity.org/ default.asp?action $=40$

[22] TIMES, Online available from http://www.iea-etsap.org/web/Times.asp

[23] ETSAP, Online available from http://www.iea-etsap.org/web/index.asp

[24] W. L. Winston, S. C. Albright, Practical Management Science, 5th Edition, CENGAGE Learning, 2016.

[25] GAMS, Online available from https://www.gams.com/

[26] GAMS Example, Online available from https://www.gams.com/docs/example.htm

[27] GAMS Library, Online available from https://www.gams.com/modlib/modlib.htm
[28] AMPL, Online available from http://ampl.com/

[29] OPL, Online available from https://www-01.ibm.com/software/commerce/ optimization/modeling/

[30] GLPK, Online available from https://www.gnu.org/software/glpk/

[31] OSeMOSYS, Online available from http://www.osemosys.org/

[32] M. Howells, H. Rogner, N. Strachan, C. Heaps, H. Huntington, S. Kypreos, A. Hughes, S. Silveira, J. DeCarolis, and M. Bazillian, OSeMOSYS: the open source energy modeling system: an introduction to its ethos, structure and development, Energy Policy, Vol. 39, No. 10, 5850-5870.

[33] OSeMOSYS Model and Data, Online available from http://www.osemosys.org/getting-started.html

[34] Natural Resources Canada Comprehensive Energy Use Database, Online available from http://oee.nrcan.gc.ca/corporate/statistics/neud/dpa/ menus/trends/comprehensive_tables/list.cfm 